\title{
Comparative Study of the Activity of Brain Behavioral Systems in Methamphetamine and Opiate Dependents
}

\author{
Marjan Alemikhah, ${ }^{1}$ Farhad Faridhosseini, ${ }^{2,}$ Hassan Kordi, ${ }^{3}$ Morad Rasouli-Azad, ${ }^{4}$ and \\ Najmeh Shahini ${ }^{5}$

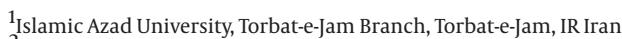 \\ ${ }_{2}^{2}$ Psychiatry and Behavioral Sciences Research Center, Ibn-e-Sina Hospital, Mashhad University of Medical Sciences, Mashhad, IR Iran \\ ${ }^{3}$ Physical Education and Sport Science Department, Ferdowsi University, Mashhad, IR Iran \\ ${ }_{5}^{4}$ Shahid Beheshti University of Medical Science and Health Services, Tehran, IR Iran \\ 5 Psychiatry and Behavioral Sciences Research Center, Student Research Committee, Ibn-e-Sina Hospital, Faculty of Medicine, Mashhad University of Medical Sciences, Mashhad, \\ IR Iran \\ ${ }^{*}$ Corresponding author: Farhad Faridhosseini, Psychiatry and Behavioral Sciences Research Center, Ibn-e-Sina Hospital, Mashhad University of Medical Sciences, Mashhad, IR Iran. Tel: \\ +98-9155115502, Fax: +98-5137112723, E-mail: faridhoseinif@mums.ac.ir
}

Received 2014 November 13; Revised 2015 March 16; Accepted 2015 April 15.

\begin{abstract}
Background: Substance dependency is a major problem for the general health of a society. Different approaches have investigated the substancedependencyin ordertoexplain it.Gray'sreinforcementsensitivity theory(RST)is an advanced and importantneuropsychological theory in this area.

Objectives: The aim of this study was to compare three systems of the revised reinforcement sensitivity theory the behavioral activation system (r-BAS), the revised behavioral inhibition system (r-BIS), and the revised fight/flight/freezing system (r-FFFS) between patients dependent on methamphetamine and opiates, and a group of controls.

Patients and Methods: This research was a causal-comparative study that was conducted in the first six months of 2012. The population of the study was males of Mashhad city, who were dependent on methamphetamine or opiates, and ruling out psychotic disorders and prominent Axis II. Twenty-five people were selected by the convenient sampling method.Also, 25 non-dependent people from the patients' relatives were selected and matched for the variables of age, gender, and education to participate in this study. Participants were evaluated using a structured clinical interview (SCID) for DSM-IV, demographic questionnaire information, and a Jackson-5 questionnaire (2009). Data were analyzed by Chi-square, K-S, and independent t-test.

Results: The methamphetamine dependent group had a higher sensitivity in the r-BAS, r-BIS, and the r-Fight and r-Freezing systems compared to the control group $(\mathrm{P}<0.05)$. However, there was no significant difference in r-Flight between the two groups $(\mathrm{P}>0.05)$. "The scores of r-BIS were also significantly higher in the methamphetamine-dependent group than the opioid-dependent and control groups. For the r-Fight variable, the methamphetamine-dependent group was higher than the opioid-dependent group".

Conclusions: The personality patterns of patients dependent on methamphetamines were different from the controls. These people have a high sensitivity to punishment cues, such as being compared in social conditions and a tendency for reinforcement and reward, because of their higher sensitivity in the behavioral inhibition and activation systems.
\end{abstract}

Keywords: Methamphetamine, Inhibition (Psychology), Reinforcement

\section{Background}

Methamphetamine dependency is a major problem for general health of a society and its consumption is significantly higher in some social groups such as youths (1, 2). Methamphetamine increases the catecholamine levels, including dopamine, which mainly affects arousal. Brain imaging studies of methamphetamine-dependent individuals have shown that they have abnormal brain structures, such as destructed gray matter, limbic and paralimbic cortex, smaller hippocampus, significantly increased white matter, destroyed medial frontal lobe, and enlarged striatum $(3,4)$. In addition, chemical and metabolic neuron-specific changes were observed in the middle part of striatum in these people $(5,6)$. A state of dopaminergic overactivity was also seen in methamphetamine-dependent individuals compared with other ad$\operatorname{dicts}(7,8)$.

Different approaches have investigated dependence on substances and attempted to explain the issue. In relation, Gray's reinforcement sensitivity theory (RST) is an advanced and important neuropsychological theory (9).

Copyright (C) 2016, Zahedan University of Medical Sciences. This is an open-access article distributed under the terms of the Creative Commons Attribution-NonCommercial 4.0 International License (http://creativecommons.org/licenses/by-nc/4.0/) which permits copy and redistribute the material just in noncommercial usages, provided the original work is properly cited. 
Gray established his theory on the two dimensions of anxiety and impulsivity (10). He explained how brain-related personality traits predispose individuals to develop psychological disorders (11). According to Gray's main reinforcement sensitivity theory, three brain motivational systems exist: 1) the aversive or behavioral inhibition system (BIS);2) the appetitive or behavioral approach system (BAS); and 3) the fight and flight system (FFS), which responds to aversive unconditional and punishment unconditional stimuli (12).

In 2000, Gray and McNaughton totally revised the RST (9). In this revised reinforcement sensitivity theory ( $\mathrm{r}$ RST), the mentioned systems are activated by different stimuli. In r-RST, the revised behavioral activation system (r-BAS) responds to positive conditional and unconditional stimuli. FFS includes a freezing reaction, along with fight and flight responses, which are responsible for responding to unavoidable threatening stimuli. The fight and flight system was changed to a revised fight/ flight/freeze system (r-FFFS), and it was assumed that $\mathrm{r}$ FFFS mediates the response to all aversive conditional and unconditional stimuli and plays the role of the punishment system, which was played by BIS in the original RST. It is believed that in r-RST, r-BIS is responsible for goal conflict resolution (13).

Studies have revealed that opioid-dependent individuals, smokers, and alcoholics have higher scores of seeking variety or BAS than control groups (14-17). Results of a study by Johnson showed that higher BAS scores can predict drug abuse and dependence in a lifetime (18). In addition, Fowls proposed that substance abuse is due to the dominance of BAS over BIS (19).

Despite previous studies, the role of BIS sensitivity in substance abuse is not clear, especially in methamphetamine consumption. Some studies of drug consumption that were carried out on the general population reported a negative correlation between sensitivity of BIS and drug abuse (20-23), while other studies reported no association in this regard (23-26). Another study reported that a strong association exists between substance abuse and BIS (27). As Bijttebier et al. pointed out in their review article in 2009, almost all studies on psycho-pathologic analysis of Gray's theory used the main theory (RST), and less used the revised theory (r-RST); this shortcoming is seen as well in studies in the field of addiction (28).

\section{Objectives}

Therefore, this research is seeking to answer the question about what the difference is in r-RST subsystems between methamphetamine and opioid dependents and non-dependent individuals.

\section{Patients and Methods}

In this causal-comparative research, 50 people who met the inclusion criteria were assigned through the convenience sampling method into two groups: one group of 25 methamphetamine dependents and one group of 25 opioid dependents. Another 25 people, who were not addicted to drugs and whose age and gender variables were matched with the groups of methamphetamine and opioid users, were also included in the study as the control group. The three groups, including the methamphetamine-dependent group, the opioiddependent group, and the control group were studied. The statistical population included non-dependent people, those referred to self-introduced withdrawal clinics (Navid and Navin), and the treatment community (TC) (22) in Mashhad from March 2012 to September 2012. They were selected using the Structured Clinical Interview for DSM-IV Axis I Disorders (SCID-I), which is a semistructured interview for making major DSM-IV Axis I diagnoses. Methamphetamine dependents were neither dependent on other drugs, nor did they consume other drugs concurrently with methamphetamine. Opioid dependents were not simultaneously dependent on methamphetamine. The number of 25 persons in each group was chosen according to a study by Hassani et al. and due to limited access to individuals who met with the inclusion criteria (29). To control the heredity variable in the control group, the selected people were relatives and family members of the patients in the methamphetamine and opioid groups. Informed consent was obtained from the subjects and the study was approved by the Ethics Committee of the Medical Sciences University of Mashhad.

\subsection{Research Tools}

A demographic variables questionnaire was administered, which included questions about age, education, marital status (single, married, others), occupational status (full time, part time, unemployed), and physical status, along with history of physical disorders, and family and legal problems. The questions were asked and recorded confidentially by a psychologist. The validity of the questionnaire was approved by three professors of clinical psychology at Mashhad University of Medical Sciences.

The Jackson- 5 is a questionnaire that provides a scale for the proper measurement of revised reinforcement sensitivity theory ( $\mathrm{r}$-RST). The questionnaire has 30 items, with six items for each subscale organized in a Likert format (1-strongly disagree, 2-disagree, 3-no opinion, 4-agree, 5-strongly agree). The Jackson-5 questionnaire has five subscales including behavior activation (r-BAS) (items 1, 6, 11, 16, 21, 26), behavior inhibition (rBIS) (items 2, 7, 12, 22, 27), fight (r-Fight) (items 3, 8, 13, 18, 23, 28), flight (r-Flight) (items 4, 9, 14, 19, 24, 29), and freezing (items 5, 10, 15, 20, 25, 30). In a study of $927 \mathrm{sub}$ jects, Jackson et al. showed, through exploratory and confirmatory factor analysis, that the questionnaire has 
a good internal reliability and construct validity. In that research, the reasonable internal consistency of items was shown using Cronbach's alpha (0.70) (30). Since reliability and validity of the Jackson-5 questionnaire was not studied in an Iranian population, and especially in addicts, in this research the questionnaire was first translated into Persian and then re-translated into English. After ensuring that the translation was correct, it was applied in a pilot study on 50 patients addicted to various substances residing in the TC in Mashhad. The internal consistency of the tool in the studied population was 0.67 , as shown by Cronbach's alpha, which shows a good internal consistency in Iranian drug-dependent people.

After completion of the questionnaires, the gathered data were analyzed through descriptive and inferential statistics. The demographic variables of the groups were compared using the Chi-square test. The KolmogorovSmirnov test was used to ensure normal distribution of the data among the two groups of methamphetamine and opioid dependents, and the independent t-test was used to compare the variables of drug consumption, age of onset, and duration. In order to compare the brain systems of the individuals, multivariate analysis of variance (MANOVA), univariate analysis of variance (ANOVA), and post hoc Scheffe tests were used. All statistical operations were performed by SPSS at the level of $\alpha=0.05$.

\section{Results}

First, the demographic variables were analyzed in all groups. The mean age of subjects in the methamphetamine-dependent and opioid-dependent groups was $28.88 \pm 3.80$ and $30.20 \pm 5.02$ years, respectively. The descriptive indices of the subjects and the results of the Chi- square test for comparison of educational level, marital status, and occupational status are shown in Table 1.

As can be seen in Table 1, there is no significant difference between the groups in terms of education ( $P$ $\left.=0.020, \chi^{2}=5.9\right)$. In addition, no significant difference was found between the groups in terms of marital status $\left(\mathrm{P}=0.272, \chi^{2}=5.15\right)$ or occupational status $(\mathrm{P}=0.65$, $\left.\chi^{2}=2.46\right)$. Next, the variables of age at onset of consumption and duration of dependence were compared in the two groups of methamphetamine dependents and opioid dependents using the independent t-test (Table 2).

The results showed that methamphetamine dependents began consuming significantly sooner than opioid dependents $(\mathrm{t}(48)=2.483$. $\mathrm{P}=0.019)$, thus they had an earlier dependence age $(\mathrm{t}(48)=2.477, \mathrm{P}=0.019)$. The age of onset of consumption of illegal substances was 16 years in methamphetamine-dependents and 19.5 years in opioid-dependents. The age of dependence onset in methamphetamine dependents and opioid dependents were 19 and 22.5 years, respectively. No difference was observed between the two groups in terms of consumption duration $(\mathrm{t}(48)=0.572, \mathrm{P}=0.571)$.

The results of multivariate analysis of variance showed that a significant difference existed between the three groups of methamphetamine dependents, opioid dependents, and controls in the combined dependent variables of the Jackson-5 Factor $(\mathrm{F}(10,136)=4.073, \mathrm{P}<0$. 001, Partial $\eta^{2}=0.230$ and Wilk's lambda $\left.=0.592\right)$.

The results of univariate analysis of variance for each subscale of the Jackson-5 questionnaire showed that a significant difference existed between the three groups in the variables of r-BAS, r-BIS, and freezing $(\mathrm{P}<0.005)$, while they had no significant difference in terms of $r$ Flight (Table 3).

Table 1. Comparison of Demographic Variables Between Methamphetamine-dependent, Opioid-dependent Groups and Controls Chi-square Test ${ }^{\mathrm{a}}$

\begin{tabular}{|c|c|c|c|c|c|}
\hline Demographic Variables & Control & Opioid-dependent & $\begin{array}{c}\text { Methamphetamine- } \\
\text { dependent }\end{array}$ & P Value & $\chi^{2}$ \\
\hline Level of Education & & & & .206 & .95 \\
\hline Guidance & $36(9)$ & $32(8)$ & $44(11)$ & & \\
\hline High school & $36(9)$ & $52(13)$ & $52(13)$ & & \\
\hline Academic & $28(7)$ & $16(4)$ & $4(1)$ & & \\
\hline Marital Status & & & & .272 & .155 \\
\hline Married & $44(17)$ & $68(17)$ & $44(11)$ & & \\
\hline Single & $28(7)$ & $32(8)$ & $48(12)$ & & \\
\hline Other & $4(1)$ & $0(0)$ & $8(2)$ & & \\
\hline \multicolumn{6}{|l|}{ Job } \\
\hline Full-time & $36(9)$ & $36(9)$ & $20(5)$ & .65 & .462 \\
\hline Part-time & $32(8)$ & $28(7)$ & $44(11)$ & & \\
\hline Unemployed & $32(8)$ & $36(9)$ & $36(9)$ & & \\
\hline
\end{tabular}

\footnotetext{
${ }^{\mathrm{a}}$ Data are presented as frequency \%.
} 
A Scheffe post hoc test was used to observe the intergroup differences (Table 4 ).

The results of this section showed that the methamphetamine-dependent group had significantly higher r-BAS and freezing scores than the control group. The scores of r-BIS were also significantly higher in the methamphetamine-dependent group than the opioiddependent and control groups. For the r-Fight variable, the methamphetamine-dependent group was higher than the opioid-dependent group, while no significant difference was seen between the three groups in terms of r-Flight scores.

Table 2. Comparison of Drug-dependent Groups in Age at Onset of Consumption, Age at Onset Dependence, and Duration of Dependence $^{\mathrm{a}}$

\begin{tabular}{lcccc}
\hline Variables & Methamphetamine-dependent & Opioid-dependent & P Value & $\mathbf{T}^{\mathbf{b}}$ \\
\hline Age at onset of consumption & $2.2 \pm 16$ & $6.6 \pm 19.48$ & .019 & 2.483 \\
Age at onset of dependence & $2.97 \pm 18.88$ & $7.06 \pm 22.68$ & .019 & 2.477 \\
Duration of the dependence & $4.04 \pm 10$ & $6.13 \pm 9.16$ & .571 & 0.572 \\
\hline
\end{tabular}

${ }^{\mathrm{a}}$ Data are presented as mean $\pm \mathrm{SD}$.

$\mathrm{b}_{\text {The condition for equality of variances. }}$

\begin{tabular}{|c|c|c|c|c|c|c|c|}
\hline Dependent Variable & Mean \pm SD & Mean Square & Square & df & $\mathbf{F}$ & PValue & $\eta^{2}$ \\
\hline \multicolumn{8}{|l|}{ Group } \\
\hline r-BAS & & 86.76 & 173.52 & 2 & 5.567 & $.006^{\mathrm{a}}$ & .134 \\
\hline Methamphetamine & $22.84 \pm 3.71$ & & & & & & \\
\hline Opiate & $20.8 \pm 4.28$ & & & & & & \\
\hline Normal & $19.12 \pm 3.82$ & & & & & & \\
\hline r-BIS & & 95.213 & 190.427 & 2 & 5.092 & $.009^{a}$ & .124 \\
\hline Methamphetamine & $24.96 \pm 3.16$ & & & & & & \\
\hline Opiate & $22.36 \pm 4.90$ & & & & & & \\
\hline Normal & $22.40 \pm 5.17$ & & & & & & \\
\hline r-Fight & $19.32 \pm 5.88$ & 150.173 & 300.347 & 2 & 7.478 & $.001^{\mathrm{a}}$ & .172 \\
\hline Methamphetamine & $14.44 \pm 3.90$ & & & & & & \\
\hline \multicolumn{8}{|l|}{ Opiate } \\
\hline Normal & $16.48 \pm 3.21$ & & & & & & \\
\hline r-Flight & & 24.333 & 48.667 & 2 & 1.784 & .175 & .042 \\
\hline Methamphetamine & $14.2 \pm 4.33$ & & & & & & \\
\hline Opiate & $15.80 \pm 2.90$ & & & & & & \\
\hline Normal & $14.00 \pm 3.69$ & & & & & & \\
\hline Freezing & & 71.773 & 143.547 & 2 & 5.635 & $.005^{\mathrm{a}}$ & .135 \\
\hline Methamphetamine & $16.12 \pm 3.87$ & & & & & & \\
\hline Opiate & $15.36 \pm 4.35$ & & & & & & \\
\hline Normal & $12.88 \pm 2.04$ & & & & & & \\
\hline
\end{tabular}

${ }^{\mathrm{a}} \mathrm{P}$ value is significant at the 0.01 
Alemikhah M et al.

Table 4. Results of Scheffé's Test to Compare Groups of the Dependent Variables Among the Subjects

\begin{tabular}{|c|c|c|c|}
\hline Dependent Variable & Differences in Average & Standard Error & P Value \\
\hline \multicolumn{4}{|l|}{ Group } \\
\hline \multicolumn{4}{|l|}{ r-BAS } \\
\hline \multicolumn{4}{|l|}{ Methamphetamine } \\
\hline Normal & 3.72 & 1.116 & $.006^{\mathrm{a}}$ \\
\hline Opiate & 2.04 & 1.116 & .196 \\
\hline \multicolumn{4}{|l|}{ Opiate } \\
\hline Normal & 1.68 & 1.116 & .328 \\
\hline Methamphetamine & -2.04 & 1.116 & .196 \\
\hline \multicolumn{4}{|l|}{ Normal } \\
\hline Opiate & -1.68 & 1.116 & .328 \\
\hline Methamphetamine & -3.72 & 1.116 & $.006^{\mathrm{a}}$ \\
\hline \multicolumn{4}{|l|}{ r-BIS } \\
\hline \multicolumn{4}{|l|}{ Methamphetamine } \\
\hline Normal & 3.36 & 1.223 & $.028^{\mathrm{b}}$ \\
\hline Opiate & 3.4 & 1.223 & $.025^{\mathrm{b}}$ \\
\hline \multicolumn{4}{|l|}{ Opiate } \\
\hline Normal & -0.04 & 1.223 & .999 \\
\hline Methamphetamine & -0.4 & 1.223 & $.025^{\mathrm{b}}$ \\
\hline \multicolumn{4}{|l|}{ Normal } \\
\hline Opiate & 0.04 & 1.223 & .999 \\
\hline Methamphetamine & -3.36 & 1.223 & $.028^{\mathrm{b}}$ \\
\hline \multicolumn{4}{|l|}{ r-Fight } \\
\hline \multicolumn{4}{|l|}{ Methamphetamin e } \\
\hline Normal & 2.84 & 1.267 & .088 \\
\hline Opiate & 4.88 & 1.267 & $.001^{\mathrm{a}}$ \\
\hline \multicolumn{4}{|l|}{ Opiate } \\
\hline Normal & -2.04 & 1.267 & .28 \\
\hline Methamphetamine & -4.88 & 1.267 & $.001^{\mathrm{a}}$ \\
\hline \multicolumn{4}{|l|}{ Normal } \\
\hline Opiate & 2.04 & 1.267 & .28 \\
\hline Methamphetamine & -2.84 & 1.267 & .088 \\
\hline \multicolumn{4}{|l|}{ Freezing } \\
\hline \multicolumn{4}{|l|}{ Methamphetamine } \\
\hline Normal & 3.24 & 1.009 & $.008^{\mathrm{a}}$ \\
\hline Opiate & 0.76 & 1.009 & .754 \\
\hline \multicolumn{4}{|l|}{ Opiate } \\
\hline Normal & 2.48 & 1.009 & .055 \\
\hline Methamphetamine & -0.76 & 1.009 & .754 \\
\hline \multicolumn{4}{|l|}{ Normal } \\
\hline Opiate & 2.48 & 1.009 & .055 \\
\hline Methamphetamine & -3.24 & 1.009 & $.008^{\mathrm{a}}$ \\
\hline
\end{tabular}

a Significant at the 0.01 .

$\mathrm{b}_{\text {Significant at the } 0.05 \text {. }}$ 


\section{Discussion}

The present study showed that the methamphetaminedependent patients began drug consumption significantly sooner than opioid-dependent patients. The age of consumption onset in methamphetamine-dependent patients and in opioid-dependent patientss was 16 and 19.5 years, respectively, which is earlier than the consumption onset shown in other studies (31). Darke et al. showed that the age of onset was 18 years in methamphetaminedependent patients and 20.5 years in opioid-dependent patients. In this study, the age of dependence onset was 19 years in methamphetamine-dependent patients and 23 years in opioid-dependent patients; this is lower than a study performed in Tehran, which reported the age of onset as 25 - 34 years (32).

Previous studies have addressed the role of the subsystems of Gray's reinforcement sensitivity theory in dependence on other substances such as alcohol (33-36), opioid, or cocaine $(12,17)$. The objective of this study was to compare the subsystems of the revised Gray's reinforcement sensitivity theory between methamphetamine-dependent and opioid-dependent patients and a non-dependent control group.

The results of this study showed that a difference existed between methamphetamine-dependent and opioiddependent patients and the control individuals in the four systems of behavioral activation, behavioral inhibition, fight, and freezing, and from the five systems of the revised Gray's reinforcement sensitivity theory ( $r-R S T$ ). However, no significant difference was observed in the flight system.

In the behavioral activation subsystem, the scores of methamphetamine-dependent patients were significantly higher than the control group; this is consistent with a majority of studies $(18,21,23,37-39)$. In fact, methamphetamine dependents have more sensitive behavioral activation than normal people. Psychotropic drugs, especially stimulants such as methamphetamine and cocaine, affect the dopaminergic system, which regulates emotional responses and leads to more positive emotional experiences (40). For high sensitivity of the behavioral activation system, some researchers use the term reward deficiency syndrome, and have investigated this as a possible factor in drug abuse development (39). Reward deficiency syndrome points out the inability to express satisfaction, resulting from a disturbance in the dopamine function in the brain reward cycle, following smoking, drug, and alcohol consumption. This syndrome is a predictor of aggressive behaviors and addiction $(37,41,42)$.

An interesting result in this study was the lack of a significant difference between opioid dependents, methamphetamine dependents, and controls in terms of the behavioral activation system. This finding is inconsistent with some previous studies, performed in Iran and other countries $(17,34,43)$. According to the results of Jackson et al., the reason for this inconsistency in the findings can be attributed to the difference in the definition of the BAS function in the main and revised theories. In the original theory, BAS is activated by reward-associated stimuli or at the end of punishment and is responsible for organization of behavior in response to pleasant stimuli, such as unconditional reward or flight from punishment. In the revised theory, r-BAS is responsible for responding to arousal stimuli, both conditional and unconditional; it is also responsible for organization of behavior in response to arousal stimuli (23).

Regarding the behavioral inhibition subsystem (BIS), the results revealed that methamphetamine dependents have a more sensitive inhibition system, when compared with opioid dependents and controls. This finding is consistent with some studies $(27,40,43)$ and inconsistent with others $(21,22,44)$. The reason for this difference is the variation in the definition of the BIS function in the main and revised theories. In the main theory, BIS has an inhibition and punishment role, while in the revised theory this system is not as inhibitory, plays a lower role in punishment, and is affected by anxiety (30).

The higher sensitivity of r-BIS in the methamphetaminedependent group means that an avoiding-defensive point of view exists toward social conflicts, social comparison, failure in attempts, uncertainty, and avoidance of social judgments of others. In comparison to opioiddependents and controls, methamphetamine consumers experience more negative emotions and more tendencies toward avoidance behaviors $(30,44,45)$.

The methamphetamine dependents had a higher sensitivity compared to the opioid dependents in the fight system, but no difference was found between the opioiddependent group and controls; this is similar to other studies $(30,40,46)$. The higher sensitivity of the fight system can be attributed to the negative effects of methamphetamine on occurrence of psychotic-like symptoms and anxiety. On the other hand, those with a high r-Flight and r-BAS have antisocial tendencies and social deviation (30). Thus, it can be concluded that the interaction of these two systems in the personality of methamphetamine dependents can explain the majority of their interpersonal and social problems, and the fight system increment in methamphetamine dependents can be due to the correlation of this system with the antisocial characteristics of these patients.

In the freezing system, those dependent on methamphetamine and opioids had more sensitivity than the controls; this finding is similar to other studies (45). Gray, McNaughton, and Jackson believe that freezing is a tendency toward mental or physical inhibition, when the person is in threatening and fearful situations $(9,31)$. In those dependent on methamphetamine and opioids, the extent of purposeful and organized behavior and response to unpleasant stimuli is reduced when compared with controls, and in threatening and unpleasant 
situations they have a higher tendency toward freezing (which has a fear basis).

So, the revised reinforcement sensitivity theory is a neurologic theory of personality, which attempts to explain the basic biologic constructs of personality. In this research, the participants in three groups (methamphetamine, opioid, and control) were so selected to be closely related, or family members, in order to have similar genetic and environmental conditions. Despite these similarities, the highest difference was seen in the two groups of methamphetamine and opioid dependents; this can explain the effect of methamphetamine on the brain structure of the consumers. The findings also showed that the sensitivity of the two systems, revised behavioral activation and inhibition, was higher in methamphetamine dependents than opioid dependents and controls, and in the revised fight/flight/freezing system, a difference existed between dependents on methamphetamine and opioids. High sensitivity of the behavioral activation and behavioral inhibition systems in methamphetamine dependents, as seen in the results of this study, confirms the higher levels of extraversion-impulsivity and tendency toward reward and punishment avoidance. Through the study of addiction and the neurobiological constructs of personality, this study tried to augment the basic knowledge of researchers in understanding the relationship between addiction, the nervous system, and the varied vulnerability of individuals. Also, it may encourage researchers in the field of the relationship of brain and behavioral systems and pathologic aspects of patients.

The limitations of the study that should be mentioned were its cross-sectional format, the small sample size due to inaccessibility to people who had the inclusion criteria, and being a single sex study due to inaccessibility to methamphetamine and opioid using women. Thus, it is suggested that this study be performed in the future more extensively and include the female population.

\section{Acknowledgments}

This study was extracted from a master thesis at the Islamic Azad University, Torbat-e-jam Branch without any organizational financial support. Hereby, the authors would like to thank sincerely all participants and colleagues who helped us perform this research.

\section{Footnote}

Authors' Contribution:Farhad Faridhosseini: writing the article, conception and design; Najmeh Shahini: obtaining findings, writing the article, final approval of the article; Marjan Alemikhah: writing the article, data collection, literature search; Najmeh Shahini: critical revision of the article, provision of materials, patients, or resources; Hassan Kordi: critical revision of the article, provision of materials, patients, or resources; Morad
Rasouli-Azad: statistical expertise; Farhad Faridhosseini: administrative support.

\section{References}

1. Postigo C, Lopez de Alda MJ, Barcelo D. Drugs of abuse and their metabolites in the Ebro River basin: occurrence in sewage and surface water, sewage treatment plants removal efficiency, and collective drug usage estimation. Environ Int. 2010;36(1):75-84. doi:10.1016/j.envint.2009.10.004. [PubMed:19913915]

2. Barr AM, Panenka WJ, MacEwan GW, Thornton AE, Lang DJ, Honer WG, et al. The need for speed: an update on methamphetamine addiction. J Psychiatry Neurosci. 2006;31(5):301-13. [PubMed: 16951733]

3. Thompson PM, Hayashi KM, Simon SL, Geaga JA, Hong MS, Sui Y, et al. Structural abnormalities in the brains of human subjects who use methamphetamine. J Neurosci. 2004;24(26):6028-36. doi:10.1523/jneurosci.0713-04.2004. [PubMed:15229250]

4. Chang L, Cloak C, Patterson K, Grob C, Miller EN, Ernst T. Enlarged striatum in abstinent methamphetamine abusers: a possible compensatory response. Biol Psychiatry. 2005;57(9):967-74. doi: 10.1016/j.biopsych.2005.01.039. [PubMed:15860336]

5. Aron JL, Paulus MP. Location, location: using functional magnetic resonance imaging to pinpoint brain differences relevant to stimulant use. Addiction. 2007;102 Suppl 1:33-43. doi: 10.1111/j.1360-0443.2006.01778.x. [PubMed: 17493051]

6. Baicy K, London ED. Corticolimbic dysregulation and chronic methamphetamine abuse. Addiction. 2007;102 Suppl 1:5-15. doi: 10.1111/j.1360-0443.2006.01777.x. [PubMed:17493049]

7. Volkow ND, Li TK. Drug addiction: the neurobiology of behaviour gone awry. Nat Rev Neurosci. 2004;5(12):963-70. doi: 10.1038/ nrn1539. [PubMed:15550951]

8. Goldstein RZ, Volkow ND. Drug addiction and its underlying neurobiological basis: neuroimaging evidence for the involvement of the frontal cortex. Am J Psychiatry. 2002;159(10):1642-52. doi:10.1176/appi.ajp.159.10.1642. [PubMed: 12359667]

9. Gray J, McNaughton N. The neuropsychology of anxiety: an enquiry into the functions of the septo-hippocampal system. Oxford: Oxford University Press; 2000.

10. Gray JA, McNaughton N. The neuropsychology of anxiety: An enquiry into the function of the septo-hippocampal system. Oxford: Oxford University Press; 2003.

11. Gray JA, van Goozen SHM, Van de Poll NE, Sergeant JA. Framework for a taxonomy of psychiatric disorder. Emotions: Essays emotion theory.1994:29-59.

12. Dawe S, Loxton NJ. The role of impulsivity in the development of substance use and eating disorders. Neurosci Biobehav Rev. 2004;28(3):343-51. doi: 10.1016/j.neubiorev.2004.03.007. [PubMed:15225976]

13. Corr PJ. Reinforcement Sensitivity Theory (RST): Introduction. New York: Cambridge University Press; 2008.

14. Pomerleau CS, Pomerleau OF, Flessland KA, Basson SM. Relationship of Tridimensional Personality Questionnaire scores and smoking variables in female and male smokers. J Subst Abuse. 1992;4(2):143-54. [PubMed: 1504639]

15. Le Bon O, Basiaux P, Streel E, Tecco J, Hanak C, Hansenne M, et al. Personality profile and drug of choice; a multivariate analysis using Cloninger's TCI on heroin addicts, alcoholics, and a random population group. Drug Alcohol Depend. 2004;73(2):175-82. [PubMed: 14725957]

16. Vukov M, Baba-Milkic N, Lecic D, Mijalkovic S, Marinkovic J. Personality dimensions of opiate addicts. Acta Psychiatr Scand. 1995;91(2):103-7. [PubMed:7778466]

17. Franken IH, Muris P, Georgieva I. Gray's model of personality and addiction. Addict Behav. 2006;31(3):399-403. doi: 10.1016/j.addbeh.2005.05.022. [PubMed: 15964149]

18. Johnson SL, Turner RJ, Iwata N. BIS/BAS levels and psychiatric disorder: An epidemiological study. Journal of Psychopathology and Behavioral Assessment. 2003;25(1):25-36.

19. Fowles DC. Biological variables in psychopathology: A psychobiological perspective. Germany: Springer; 2002. pp. 85-104.

20. Genovese JE, Wallace D. Reward sensitivity and substance abuse 
in middle school and high school students. J Genet Psychol 2007;168(4):465-9. doi: 10.3200/gntp.168.4.465-469. [PubMed: 18232522]

21. Simons JS, Dvorak RD, Batien BD. Methamphetamine use in a rural college population: associations with marijuana use, sensitivity to punishment, and sensitivity to reward. Psychol Addict Behav. 2008;22(3):444-9. doi: 10.1037/0893-164x.22.3.444. [PubMed 18778139]

22. Hundt NE, Kimbrel NA, Mitchell JT, Nelson-Gray RO. High BAS, but not low BIS, predicts externalizing symptoms in adults. Pers Indiv Differ. 2008;44(3):565-75.

23. Loxton NJ, Dawe S. Reward and punishment sensitivity in dysfunctional eating and hazardous drinking women: associations with family risk. Appetite. 2006;47(3):361-71. doi: 10.1016/j.appet.2006.05.014. [PubMed:16846665]

24. Loxton NJ, Nguyen D, Casey L, Dawe S. Reward drive, rash impulsivity and punishment sensitivity in problem gamblers. Pers Indiv Differ. 2008;45(2):167-73.

25. Loxton NJ, Dawe S. How do dysfunctional eating and hazardous drinking women perform on behavioural measures of reward and punishment sensitivity? Pers Indiv Differ. 2007;42(6):1163-72.

26. O'Connor RM, Stewart SH, Watt MC. Distinguishing BAS risk for university students' drinking, smoking, and gambling behaviors. Pers Indiv Differ. 2009;46(4):514-9.

27. Taylor J, Reeves M, James L, Bobadilla L. Disinhibitory trait profile and its relation to cluster B personality disorder features and substance use problems. EurJ Person. 2006;20(4):271-84. doi 10.1002/per.585.

28. Bijttebier P, Beck I, Claes L,Vandereycken W. Gray's Reinforcement Sensitivity Theory as a framework for research on personalitypsychopathology associations. Clin Psychol Rev. 2009;29(5):42130. doi:10.1016/j.cpr.2009.04.002. [PubMed:19403216]

29. Hasani J, Bigdeli I, Goshchiyan S. The activity of brain/behavioral systems in patients with obsessive-compulsive disorder in comparison with normal individuals. Adv Cogn Sci. 2008:16-25.

30. Jackson CJ. Jackson-5 scales of revised Reinforcement Sensitivity Theory (r-RST) and their application to dysfunctional real world outcomes. J Res Person. 2009;43(4):556-69.

31. Khodabandeh F. Gender Difference in the Characteristics among Unintentional Methamphetamine Overdose Patients Referring to Poison Center-an Epidemiologic Survey. Int J Med Toxicol Forensic Med. 2013;3(3):80-7.

32. Darke S, Kaye S, Torok M. Age-related patterns of drug use initiation among polydrug using regular psychostimulant users. Drug Alcohol Rev. 2012;31(6):784-9. doi: 10.1111/j.1465-3362.2012.00436.x. [PubMed: 22449025]

33. Lopez-Vergara HI, Colder CR, Hawk Jr LW, Wieczorek WF, Eiden $\mathrm{RD}$, Lengua LJ, et al. Reinforcement sensitivity theory and alcohol outcome expectancies in early adolescence. Am J Drug Alcohol Abuse. 2012;38(2):130-4. doi: 10.3109/00952990.2011.643973. [PubMed: 22220630]
34. Kambouropoulos N, Staiger PK. Reactivity to alcohol-related cues: relationship among cue type, motivational processes, and personality. Psychol Addict Behav. 2004;18(3):275-83. doi 10.1037/0893-164x.18.3.275. [PubMed:15482083]

35. Wardell JD, Read JP, Colder CR, Merrill JE. Positive alcohol expectancies mediate the influence of the behavioral activation system on alcohol use: a prospective path analysis. Addict Behav. 2012;37(4):435-43. doi: 10.1016/j.addbeh.2011.12.004. [PubMed: 22209025]

36. Pardo Y, Aguilar R, Molinuevo B, Torrubia R. Alcohol use as a behavioural sign of disinhibition: evidence from J.A. Gray's mode of personality. Addict Behav. 2007;32(10):2398-403. doi: 10.1016/j. addbeh.2007.02.010. [PubMed:17407802]

37. Blum K, Chen AL, Oscar-Berman M, Chen TJ, Lubar J, White N, et al. Generational association studies of dopaminergic genes in reward deficiency syndrome (RDS) subjects: selecting appropriate phenotypes for reward dependence behaviors. Int J Environ Res Public Health. 2011;8(12):4425-59. doi: 10.3390/ijerph8124425. [PubMed: 22408582]

38. Moradi AA. Brain, behavior, and mental health in substance dependent individuals in comparison to healthy controls. Jo fund men health. 2012;13(4):304-13.

39. Loxton NJ, Dawe S. Alcohol abuse and dysfunctional eating in adolescent girls: the influence of individual differences in sensitivity to reward and punishment. Int J Eat Disord. 2001;29(4):455-62. [PubMed: 11285583]

40. Abdi R, Bakhshipour Roudsari A, Mahmood Aliloo M. The sensitivity level of behavioral approach and inhibition systems in substance abusers, smokers and normal subjects. Iranian $j$ psy chiatry clin psychol.2011;17(3):241-7.

41. Comings DE, Blum K. Reward deficiency syndrome: genetic aspects of behavioral disorders. Prog Brain Res. 2000;126:325-41 doi:10.1016/s0079-6123(00)26022-6. [PubMed:11105655]

42. Blum K, Gardner E, Oscar-Berman M, Gold M. "Liking" and "wanting" linked to Reward Deficiency Syndrome (RDS): hypothesizing differential responsivity in brain reward circuitry. Curr Pharm Des. 2012;18(1):113-8. [PubMed: 22236117]

43. Pourmohseni KF, Haghshenas A, Asadi S. A Comparison OF brainbehavioral systems and gender differences among addicted and non-addicted persons. 2011;13(50):9-22.

44. Fahimi S, Ali MM, Bakhshipour RA, Mahmood AM. GRAY'S biological model of personality and addiction(Persian).J Psychiatry Clin Psychol.2012;6:51-60.

45. Perkins AM, Kemp SE, Corr PJ. Fear and anxiety as separable emotions: an investigation of the revised reinforcement sensitivity theory of personality. Emotion. 2007;7(2):252-61. doi:10.1037/15283542.7.2.252. [PubMed: 17516804]

46. Abdalehzade-Jeddi A, Hashemi MA, Nosratabad T, Moradi AR. The Role of brain behavioral systems in predicting of drug abuse. $J$ clin psychol. 2010;2:6. 